\title{
Smokeless tobacco use among adolescents in Ilala Municipality, Tanzania
}

\author{
P. KADURI ${ }^{1}$, H. KITUA ${ }^{2}$, J. MBATIA ${ }^{3}$, A.Y. KITUA ${ }^{4 *}$ and J. MBWAMBO ${ }^{1}$ \\ ${ }^{1}$ Muhimbili University of Health and Allied Sciences, Dar es Salaam, Tanzania \\ ${ }^{2}$ Tumaini University, Iringa, Tanzania \\ ${ }^{3}$ Ministry of Health and Social Welfare, Dar es Salaam, Tanzania \\ ${ }^{4}$ National Institute for Medical Research, P.O. Box 9653, Dar es Salaam, Tanzania
}

\begin{abstract}
Smokeless tobacco use is a significant part of the overall world tobacco problem. When the habit is introduced early in life, it increases the chance for permanent addiction and primes adolescents for use of harder drugs, exposing them to higher risk of oral cancer and other adverse effects of tobacco. This baseline study aimed at providing descriptive information on smokeless tobacco knowledge and use among adolescents at a time just before the ban on such products was enforced nationally on $1^{\text {st }}$ December 2006. Six out of 101 primary and four out of 11 secondary schools were randomly selected in Ilala Municipality, Tanzania. A total of 1011 students were randomly selected and interviewed; boys (mean age $=14.5$ years) accounted for $50.7 \%$ and girls (mean age $=13.6$ years) $49.3 \%$. The prevalence of tobacco use was $5.9 \%$ (boys $=9 \%$; girls $=2.4 \%$ ). Prevalence of smokeless tobacco use was 3.6\%, about half of all who have ever smoked. Most popular brand of smokeless tobacco reported was Kuberi (44.8\%) followed by Gutka (6.9\%). Twelve (41\%) of the smokeless tobacco users were using the products almost everyday. Among the reasons reported for smokeless tobacco use were pleasure $(27.6 \%)$, smell $(17.2 \%)$ and taste $(6.9 \%)$. However, $48.3 \%$ of the users did not know why they used the product for the first time. Smokeless tobacco products were branded as nutritional supplements with different tastes and strengths, ideal for enticing the curiosity of adolescents. Given the crafty practice of the tobacco industry and salesmen, there is need for monitoring of availability of these products in circulation and enforcement of the ban nationally and globally to institute measures for effective elimination of this harmful practice.
\end{abstract}

Key words: smokeless, tobacco, adolescents, Tanzania

\section{Introduction}

Smokeless tobacco use is a significant part of the overall world tobacco problem. These are products of tobacco without combustion at time of use but containing nicotine and other carcinogenic components, which are hazardous to health. Smokeless tobacco products have not received the same adverse publicity as smoking tobacco despite being equally life threatening. Use of smokeless tobacco products is common and occurs in various forms such as chewed, sucked, snuffed or applied to teeth and gums. Various products both processed and un-processed including Gutka, Rozana, Tulsi and Kuberi, are available in the market.

Tobacco use in general has been a growing problem worldwide causing large number of deaths (Peto et al., 1999). Tobacco currently is responsible for 1 in 10 adult deaths and by 2030 it is expected to be 1 in 6 or 10 million deaths annually, the rate that exceed any other cause of death. It is projected that 7 out of every 10 such deaths will be in low and middle income countries (WHO, 1999). Sales of smokeless tobacco have increased over $11 \%$ in the USA since 1974 and adolescent use of smokeless tobacco is also increasing
(Lichtensten et al., 1984). These smokeless tobacco products, such as snus and snuff, previously popular in a limited number of countries, are being marketed heavily elsewhere to specific target groups. These include women in cultures where it is not socially acceptable for females to smoke; young people presented with flavoured and milder-tasting "starter" products or to smokers as an alternative in smoke-free environments (WHO, 2006). Africa including Tanzania has been a focus of marketing activities in recent years (World Bank Report, 2003). By end of 2006, there were ongoing promotional activity campaigns targeting primary school children in Tanzania.

Adolescent period is a crucial stage that faces many attractive choices and challenges that may influence them and change their lifestyles. Use of tobacco products in this stage may results towards dependence on nicotine early in life which leads to strong addiction (WHO, 1998) and difficulty in quitting tobacco using behaviour. The use of smokeless tobacco is more likely to precede cigarette smoking, which has been addressed as a gateway drug to other substances of abuse let alone the long-term effects associated with the drug (Hatsukami et al., 1991). The current trend of Chewing tobacco at an early age is of serious concern

* Correspondence: Dr Andrew Y. Kitua; Email: akitua@nimr.or.tz 
considering the long term period for manifestation of adverse effects. Serious adverse manifestations such as cancers to early users will peak during their middle ages when such population group are in their productive years (Millennium Development Goals and Tobacco Control, 2004). The World Health Organization reports that 3 out of 5 adolescents who experiment with any form of tobacco will become addicted and daily smokers in adulthood, half of which will die prematurely (WHO, 1998).

The pattern of use varies across the globe, with relatively higher prevalence in the South Asian region (India, Pakistan, Bangladesh, China and Thailand), United States of America and Brazil. Smokeless tobacco use among adolescents has also been reported in South Africa (Gupta \& Warnakulasuriya, 2002) and in Kenya (Ogwell et al., 2003). In Tanzania, the use of tobacco products in general has been on the low side compared to other countries especially developed ones. On the other hand little is known about use of tobacco products let alone smokeless tobacco among adolescents. Protection of children is a paramount duty and obligation of any nation and it important to be vigilant to any threat directed such age groups so that appropriate interventions are designed to reduce such threats. This study therefore, aimed at providing descriptive information on the smokeless tobacco use status among adolescents at a time just before the ban of such products was enforced nationally in December 2006. Findings of this study are expected to raise awareness of the problem and provide some baseline information that is important in designing appropriate interventions and future monitoring strategies.

\section{Materials and Methods}

\section{Study area and design}

The study was carried out in Ilala Municipality in Dar es Salaam, Tanzania. The municipal had a total of 112 Public schools at the time of study. There were 101 primary and 11 public secondary schools.

A random sampling technique was used to identify and select six primary and four secondary schools as the research population. The Ministry of Education and Vocational Training and Ilala Municipal Council provided a list of all students enrolled in upper primary school grades $(5,6,7)$ and lower secondary school grades (Form I, II, III). At the school level, random sampling was done within selected grades and sex. The sample size was estimated at 1020 students.
However a total of 1011 students were available for the interview.

Data were collected by a self-administered questionnaire in a classroom after informed verbal consent had been obtained. Two females trained research assistants introduced themselves to the students and explained the purpose of the study. Time available for filling the questionnaire was between 30 to 45 minutes.

\section{Ethical consideration}

Permission to conduct the study was sought from the Ministry of Education and Vocational Training as well as from respective school authorities. The The Medical Research Coordination Committee of the National Institute for Medical Research granted ethical clearance for the study.

\section{Results}

\section{Demographic characteristics}

A total number of 1010 students filled and returned the questionnaire. Of these, 512 were boys $(50.7 \%)$ and $498(49.3 \%)$ were girls. The mean age for boys was 14.5 years $($ Standard deviation $=2.47$ ) and that for girls was 13.6 years (Standard deviation $=1.87$ ). Over half $(52.6 \%)$ of the interviewed students were christians, the rest were either muslims $(46.7 \%)$ or other religions $(0.7 \%)$. Majority were indigenous black Tanzanians $(92.7 \%)$ and other included Indians (5.4\%) and Arabs (2.0\%).

Most (77.4\%) of the respondents were raised in urban settings. Others were either raised in rural settings $(8.1 \%)$ or in mixed urban and rural settings $(14.5 \%)$. Paternal income was through paid employment (45.8\%). Maternal income was equal for those who reported paid employment (32\%) or self-employment $(31.6 \%)$. A quarter of the mothers were reported as unemployed. Forty five percent of the students reported their fathers to have attained higher level of education; only $6.5 \%$ of the students' fathers had no formal education. Only $32.6 \%$ of the mothers had attained higher education (Table 1).

\section{Use of smokeless tobacco}

The overall prevalence of ever used tobacco was $5.89 \%$. Boys were on the average 3.9 times more likely to smoke $(9 \%)$ than girls $(2.4 \%)$ with OR $(95 \% \mathrm{CI})$ of $3.9(2.09,7.6)$. Half of the ever lifetime tobacco users (50\%) reported use of smokeless tobacco product, making a prevalence of ever used smokeless tobacco 
Table 1: Socio-economic characteristics of the parents of the respondents in Ilala Municipality

\begin{tabular}{llll}
\hline Demographic characteristics & & $\mathbf{N}$ & \% \\
\hline Father occupation & Unemployed & 27 & 2.7 \\
& Self employed & 320 & 31.6 \\
& Paid employed & 463.8 & 14.0 \\
& Father absent & 141 & 24.6 \\
Mother occupation & Unemployed & 246 & 31.6 \\
& Self employed & 316 & 32.0 \\
& Paid employed & 320 & 8.5 \\
Father level of education & Mother absent & 85 & 6.5 \\
& No formal education & 65 & 9.2 \\
& Primary education & 92 & 13.1 \\
& Secondary education & 132 & 45.1 \\
Mother level of education & Higher education & 453 & 14 \\
& Father absent & 141 & 3.7 \\
& No formal education & 37 & 21.4 \\
& Primary education & 215 & 21.2 \\
\hline
\end{tabular}

to be $3.65 \%$. Of those who had ever used smokeless tobacco, oral- powdered was the commonest reported form of use. The age of onset was 12 years or less (57\%), with $28.5 \%$ being less than 10 years of age. Most popular brand of smokeless tobacco reported was Kuberi (44.8\%) followed by Gutka (6.9\%) with Lucky and Tulsi being the least reported product among many others. Twelve (41\%) of the smokeless tobacco users reported to be daily users, using the product almost everyday. Among the reasons reported for smokeless tobacco use was pleasure (27.6\%), smell (17.2\%), taste $(6.9 \%)$ and $48.3 \%$ did not know why they used the product for the first time (Table 2). Among the smokeless tobacco users snuff in form of oral placing in gingival grooves was the most frequent reported method of use.

Most of the smokeless tobacco experimenters $(59 \%)$ knew the products via advertisements from Internet sources, radio, televisions or magazines (Table $3)$. Three $(13.6 \%)$ respondents reported knowing the product via friends. About half $(51 \%)$ of the ever users did not know whether or not the products contained nicotine. However $(31.0 \%)$ knew about it and about $(17.2 \%)$ responded that the products did not contain nicotine. About one third (28.5\%) of the smokeless tobacco experimenters believed that using smokeless tobacco products was safer than smoking cigarette. However, a proportion of the experimenters (44.4\%) did not know whether there is any law or legislature that restricts the use of tobacco to adolescents.

\section{Discussion}

The study found the prevalence of tobacco use in general to be higher than smokeless tobacco use. These rates are somewhat lower than those reported from western countries and South Eastern Asia (WHO, 1988; Rouse, 1989). Among African countries a higher prevalence of about $9 \%$ among students has been reported in South Africa (Peltzer, 2003) and Kenya (Ogwell et al., 2003). A low prevalence (1.9\%) of oral tobacco snuff has also been reported among individual 15-36 years old in rural Moshi in northern Tanzania (Mnyika et al., 2006). In our study boys were two times more likely to use smokeless tobacco products than girls. These findings are similar to other studies elsewhere (Hatsukami et al., 1991; OSH, 1994). In Asians and most black populations as in South Africa, females have been found to use more frequently smokeless tobacco than males, which may be due to the cultural stigma associated with females smoking cigarettes in an African setting. On the other hand, recent data show that the prevalence of current smoking among in-school adolescents in northen Tanzania is $3.0 \%$ and $1.4 \%$ in males and females, respectively (Siziya et al., 2007).

The mean age 10 years of cigarette smoking onset among students in Dar es Salaam has been previously reported recently by Kaduri et al. (2005). Students in Dar es Salaam start smoking at a younger age than in South Africa (12.5 years) and in United States (13 
Table 2: Smokeless tobacco pattern of use and behaviour among students in Ilala Municipality

\begin{tabular}{|c|c|c|c|}
\hline Variable category & & $N(29)$ & $\%$ \\
\hline \multirow[t]{5}{*}{ Age of onset } & $\leq 10$ years & 8 & 28.6 \\
\hline & $11-12$ years & 8 & 28.6 \\
\hline & 13-14 years & 9 & 32.1 \\
\hline & $15-16$ years & 2 & 7.1 \\
\hline & $17-18$ years & 1 & 3.6 \\
\hline Preferred brand of smokeless & Kuberi & 13 & 44.8 \\
\hline \multirow[t]{4}{*}{ tobacco } & Gutka & 2 & 6.9 \\
\hline & Tulsi & 1 & 3.4 \\
\hline & Lucky & 1 & 3.4 \\
\hline & Others & 12 & 41.4 \\
\hline \multirow[t]{2}{*}{ Pattern of use } & Use everyday & 12 & 41.0 \\
\hline & Not using everyday & 17 & 59.0 \\
\hline \multirow[t]{4}{*}{ Reason for chewing } & Taste & 2 & 6.9 \\
\hline & Smell & 5 & 17.2 \\
\hline & Pleasure & 8 & 27.6 \\
\hline & Do not know & 14 & 48.3 \\
\hline
\end{tabular}

Table 3: Knowledge and attitudes associated with smokeless tobacco use among students in Ilala

\begin{tabular}{|c|c|c|c|}
\hline Question & Variable & Number & Percent \\
\hline $\begin{array}{l}\text { How did you come to } \\
\text { know about } \\
\text { smokeless tobacco }^{1}\end{array}$ & $\begin{array}{l}\text { Advertisement } \\
\text { Friend use } \\
\text { Family } \\
\text { Displayed on shop } \\
\text { Others }\end{array}$ & $\begin{array}{c}13 \\
3 \\
2 \\
1 \\
3\end{array}$ & $\begin{array}{l}59.1 \\
13.6 \\
9.1 \\
4.6 \\
13.6\end{array}$ \\
\hline $\begin{array}{l}\text { Do you know that } \\
\text { smokeless tobacco } \\
\text { contains nicotine }\end{array}$ & $\begin{array}{l}\text { Yes } \\
\text { No } \\
\text { Do not know }\end{array}$ & $\begin{array}{c}9 \\
5 \\
15\end{array}$ & $\begin{array}{l}31.0 \\
17.2 \\
51.7\end{array}$ \\
\hline $\begin{array}{l}\text { Is smokeless tobacco } \\
\text { safer than cigarettes }{ }^{2}\end{array}$ & $\begin{array}{l}\text { Yes } \\
\text { No } \\
\text { Do not know }\end{array}$ & $\begin{array}{c}8 \\
10 \\
10\end{array}$ & $\begin{array}{l}28.6 \\
35.7 \\
35.7\end{array}$ \\
\hline $\begin{array}{l}\text { Are you aware of any } \\
\text { legal smokeless } \\
\text { tobacco restriction }^{3}\end{array}$ & $\begin{array}{l}\text { No restriction } \\
\text { Restriction existing } \\
\text { Do not know }\end{array}$ & $\begin{array}{c}3 \\
12 \\
12\end{array}$ & $\begin{array}{l}11.1 \\
44.4 \\
44.4\end{array}$ \\
\hline
\end{tabular}

years) (Peltzer, 2003; Glover et al., 1989). Children as young as $\leq 5$ years old have been reported smoking cigarette in London (Farrand et al., 2001). However this present study did not look into the relationship between onset of cigarette smoking and smokeless tobacco use. Already some findings from elsewhere have shown that the higher the frequency of cigarette use, the greater the likelihood of experimenting with smokeless tobacco and vice versa (Riley et al., 1996).

The reasons for using smokeless tobacco were pleasure, smell and taste.However, a greater proportion of the experimenters did not know the reasons for using it. This may be explained by the limited options on the current questionnaire but could be that they started from mere curiosity, a common feature of adolescents. Similar findings have been found in a study done in the United States (Boyle et al., 1998) where pleasure and relaxation were the main reasons for use of smokeless tobacco. Interestingly findings from South Africa showed that the major reasons were medicinal purpose, pleasure/ taste, expectation from friends and ritual process (Peltzer, 2003). A large proportion of the smokeless tobacco users first knew about smokeless tobacco via advertisement. Similarly, Peltzer (2003) observed 4\% of the current users were most influenced by advertisements in their decision to take a tobacco product. This means that a ban on 
direct advertisements of all tobacco products on media is crucial. The current ban on smokeless tobacco sale should be strengthened by a total ban on advertising the use of any tobacco products.

A noteworthy finding was that one third of the smokeless tobacco experimenters thought that smokeless tobacco use was safer than using cigarettes. This notion may be explained by the fact that more than half of the experimenters were not aware that the smokeless products contain nicotine. There is a need for increased public health education on effects of tobacco use to and such programmes should emphasize that all tobacco products are dangerous and that are highly addictive in nature regardless of whether they are consumed through smoking or otherwise. It has been pointed out that since health related habits develop early in life, interventions targeted at children and adolescents are important for aiding change and preventing adult diseases and health risk behaviours (Sullivan, 1998)

There are limitations to our study. The limited size of population of interest i.e. the small percentage of respondents using smokeless tobacco has affected the possibility of exploring significant associations between the dependant variables of smokeless versus non smokeless users. As it may be common with self reported questionnaires the participants may have under reported their smokeless use status.

In conclusion, the results of this study have shed light on the fact that smokeless tobacco use is common among adolescents. While we commend the Ministry of Health and Social Welfare for banning smoking, strict monitoring of the enforcement of the ban is required to ensure that the importation and distribution of the products is stopped.

\section{Acknowledgements}

This study received financial support the Tanzania Health Research Users Trust Fund. We would like to thank anonymous reviewers for their critical comments in the earlier version of the manuscripts.

Received 28 October 2007

Revised 25 December 2007

Accepted 25 December 2007

\section{References}

Boyle, R.G., Gerend, M.A., Peterson, C.B. \& Hatsukami, D.K. (1998) Use of smokeless Tobacco by young adult females. Journal of Substance Abuse 10, 19-25
Farrand, P., Rowe, R.M., Johnston, A. \& Mundoch, H. (2001) Prevalence, age of onset and demographic relationship of different areca nut habits amongst children in Tower Hamlets, London. British Dental Journal 190, 150154.

Glover, E.D., Laflin, M., Flanner, D. \& Albritton, O.L (1989) Smokeless tobacco use among American college students, Journal of American College Health 38, 81-85.

Gupta, P.C. \& Warnakulasuriya, S. (2002) Global epidemiology of areca nut usage. Addiction Biology 7, 77-83.

Hatsukami, D., Nelson, R. \& Jensen, J. (1991) Smokeless tobacco: current status and future directions. Addiction 86, 559-563.

Kaduri, P., Gilreath, T., Mbwambo, J., King, G., Kilonzo G., Flisher, A.J. \& Mathews, S. (2005) Social networks influence on tobacco use among students in Dar es salaam, Tanzania. IUHPE-Promotion and Education 12, 1014.

Mnyika, K.S., Klouman, E \& Klepp, K.I (2006) Cigarette smoking and use of smokeless tobacco in Moshi rural district in Northern Tanzania. East African Journal of Public Health. 3, 24-27.

Ogwell, E.O., Astrom, A.N. \& Haugejorden, O (2003) Socio-demographic factors of pupils who use tobacco in randomly-selected primary schools in Nairobi Province, Kenya. East African Medical Journal 80, 235-241.

OSH (1994) Preventing tobacco use among young people. Office on Smoking and Health. A Report of the Surgeon General, Atlanta, Georgia.

Peltzer, K. (2003) Smokeless tobacco and cigarette use among black secondary school students in South Africa. Substance Use \& Misuse 38, 1003-1016.

Peto, R., Chen, Z.M \& Boreham, J. (1991) Tobacco - the growing epidemic.Nature Medicine 5, 15-17.

Riley, W.T., Kaugars, G.E., Grisius, T.M., Page, D.G., Burns, J.C. \& Svirsky, J.A. (1996) Adult smokeless tobacco use and age of onset. $A d$ dictive Behaviors 21, 135-138.

Rouse, B.A. (1989) Epidemiology of smokeless tobacco use: a national study. National Cancer Institute Monographs 8, 29-33.

Siziya, S., Ntata, P.R.T., Rudatsikira, E., Makupi, C.M., Umar, E. \& Muula, A.S. (2007) Sex 
differences in prevalence rates and predictors of cigarette smoking among in-school adolescents in Kilimanjaro, Tanzania. Tanzania Health Research Bulletin 9, 190-195.

Sullivan, K.T (1998) Promoting Behaviour Change. ERIC Digest available on www.eric.ed.gov

The Millennium Development Goals and Tobacco control (2004) available on www.who.int/ tobacco.

WHO (1988) Smokeless Tobacco Control. Technical Report. ISSN 0512-3054 Switzerland available on http://www.who.int
WHO (1998) World Health Report. World Health Organization, Geneva available on http://www. who.int

WHO (1999) Making a Difference. World Health Organization Geneva, Switzerland available on http://www.who.int/whr/1999

WHO (2006) Regulation Urgently Needed to Control Growing List of Deadly Tobacco Products. Available on www.who.int

World Bank Report (2003) Tobacco control country profiles: available on http://siteresources. worldbank.org/INTETC/Resources/375990111210676927 